Jeremy J. Ramsden

\title{
Bildtechnologien in zeitgenössischer naturwissenschaftlicher Fachliteratur
}

ABSTRACT. The history and contemporary use of illustrations in scientific books and, especially, research papers is explored. It is concluded that nowadays such illustrations are often used for purely meretricious effect, and can actually detract from any solid message that a paper is trying to convey. More often, however, the motivation for including them may be to mask the absence of any solid message. These trends have been enormously exacerbated by the sheer ease of producing pictures in bright colours using modern printing and online technologies. Many magazines, in which formerly substantial articles could be found, are now almost wholly given over to illustrations, which often bear scant relevance to the text. Even old-established and ostensibly respectable journals now demand "graphical abstracts" from authors, as if the contents were addressed to those who cannot read. The essay concludes by showing the value of carefully chosen illustrations in a mathematical example.

Nanotechnology Perceptions 14 (2018) 26-37

doi: 10.4024/N18RA10A.ntp.14.01 